\title{
Enraizamento de estacas caulinares de quatro espécies do gênero Tibouchina Aubl. (Melastomataceae Juss.) $)^{(1)}$
}

\author{
MICHELE FERNANDA BORTOLINI(2); JULIANA LISCHKA SAMPAIO MAYER(3); KATIA CHRISTINA ZUFFELLATO-RIBAS(4); \\ HENRIQUE SOARES KOEHLER(5) e ANTONIO APARECIDO CARPANEZZI(6)
}

\begin{abstract}
RESUMO
O gênero Tibouchina Aubl. (Melastomataceae Juss.) apresenta cerca de 200 espécies distribuídas em todo o Brasil e é recomendado como ornamental em função de sua bela floração. Este trabalho buscou avaliar o enraizamento de estacas caulinares de Tibouchina fothergillae, T. granulosa, T. pulchra e T. sellowiana com a utilização diferentes concentrações de ácido indolbutírico (AIB). Estacas semilenhosas foram confeccionadas na primavera de 2004, com $10 \mathrm{~cm}$ de comprimento e um par de folhas reduzidas pela metade. Os tratamentos foram 0,1500 e $3000 \mathrm{mgL}^{-1} \mathrm{AIB}$, em solução alcoólica (50\%) por 10 segundos. $\mathrm{O}$ plantio foi realizado em tubetes com vermiculita de granulometria média, mantidos em casa de vegetação climatizada por 30 dias para T. fothergillae; as demais espécies, por 70 dias, quando se avaliou o percentual de enraizamento, número e comprimento das raízes formadas, percentual de estacas com calos e a sua sobrevivência. $\mathrm{O}$ delineamento utilizado foi o inteiramente casualizado em arranjo fatorial de três concentrações AIB e quatro espécies do gênero Tibouchina, com quatro repetições de 20 estacas cada uma. A espécie que apresentou maior porcentagem de enraizamento foi $T$. fothergillae (100\%). T. sellowiana, T. pulchra e T. granulosa apresentaram, respectivamente, médias gerais de enraizamento de $57,50 \%, 26,67 \%$ e $16,67 \%$. A concentração que representou maior efeito sobre a porcentagem de enraizamento foi 3000 $\mathrm{mgL}^{-1}$ AIB (59,68\%). Estacas de T. fothergillae tratadas com $3000 \mathrm{mgL}^{-1}$ AIB apresentaram o maior número de raízes por estaca $(39,57)$, enquanto estacas de T. granulosa, sem o uso do AIB, apresentaram o maior comprimento médio de raízes $(13,14)$.
\end{abstract}

Palavras-chaves: quaresmeira, estaquia, ácido indolbutírico.

\section{Stem cutting of four species from the genus Tibouchina Aubl. (Melastomatacea Juss.)}

\begin{abstract}
The genus Tibouchina Aulb. (Melastomatacea Juss.) presents two hundred species approximately in Brasil and is recommended for ornamental use because its beautiful flowers. This work aimed the rooting response for stem cuttings of Tibouchina fothergillae, T. granulosa, T. pulchra and T. sellowiana using different concentrations of indolebutyric acid (IBA). The semi hardwood cuttings were produced in spring $/ 2004$ with $10 \mathrm{~cm}$ length, maintaining a pair of half leaves. The cuttings bases were treated with 0,1500 and $3000 \mathrm{mgL}^{-1} \mathrm{IBA}$, in alcoholic solutions $(50 \%)$ for ten seconds. They were planted in polypropylene boxes with medium vermiculite and maintained for 30 days to T. fothergillae and 70 days to others species in greenhouse, when were evaluated rooting percentage, length and number of roots, cutting with callus percentage and its survival. Data were analyzed using a completely randomized in a factorial arrangement for three different concentrations of IBA and four species tested with four replications and twenty cuttings to experimental unit. The species which presented the higher rooting percentage was T. fothergillae (100\%). T. sellowiana, T. pulchra and T. granulosa showed $57.70 \%, 26.67 \%$ and $16.67 \%$ of rooting, respectively. The concentration which represented the biggest effect on rooting percentage was $3000 \mathrm{mgL}^{-1} \mathrm{IBA}(59,68 \%)$. Cuttings of $T$. fothergillae treated with $3000 \mathrm{mgl}^{-}$ ${ }^{1}$ IBA showed the biggest number of roots (39.57) while cuttings of T. granulosa without IBA presented the higher average length of roots $(13,14)$.
\end{abstract}

Key-words: Indolebutyric acid, propagation e rooting.

\footnotetext{
(1) Trabalho desenvolvido no Setor de Ciências Biológicas, do Departamento de Botânica, da Universidade Federal do Paraná (UFPR). Recebido para publicação em 10 de outubro 2007 e aprovado em 21 de agosto de 2008

(2) Bióloga, Doutoranda do Curso de Agronomia - Produção Vegetal - UFPR. Bolsista do CNPq, mibortolini@hotmail.com

(3) Bióloga, Mestre em Agronomia - Produção Vegetal - UFPR.

(4) Bióloga, Doutora, Professora Associada do Departamento de Botânica, Setor de Ciências Biológicas - UFPR. Caixa Postal 19031, 81531-970

Curitiba (PR), kazu@ufpr.br

(5) Engenheiro Florestal, Doutor, Professor Adjunto do Departamento de Fitotecnia e Fitossanitarismo, Setor de Ciências Agrárias - UFPR.

${ }^{\left({ }^{(}\right)}$Engenheiro Florestal, Doutor, Pesquisador da Embrapa Florestas, Colombo (PR).
} 


\section{INTRODUÇÃO}

A família Melastomataceae possui cerca de 3.500 espécies e se distribui nas regiões tropicais e subtropicais do globo, sobretudo na América. No Brasil, ocorrem aproximadamente 63 gêneros com cerca de 480 espécies sendo Miconia, Leandra e Tibouchina os de maior representação (BARROSO, 1991). Tibouchina tem cerca de 200 espécies, com elevado número de exemplares no Brasil, encontrados em quase todos os Estados, com predominância na região Sudeste. Além do Brasil, foi localizada nos demais países da América do Sul e em quase todos os da América Central (SOUZA, 1986).

As plantas da família Melastomataceae são consideradas pioneiras, encontradas em clareiras, normalmente em ambientes degradados com solos pobres (TABARELLI e MANTOVANI, 1999; LIMA et al., 2003). Em geral, apresentam imenso potencial ornamental, sendo recomendadas para arborização de praças e jardins em razão da sua forma bem copada e da bela floração, do porte e da folhagem (PIO CORRÊIA, 1974; SOUZA, 1986). Alguns exemplares são empregados como indicadores biológicos, como é o caso de T. pulchra (Cham.) Cogn. que é utilizada no biomonitoramento ambiental da Floresta Atlântica (MORAES et al., 2000).

O uso de espécies nativas, sob o ponto de vista econômico ou com objetivo de recuperação de ecossistemas degradados, sempre foi uma atividade rentável, necessária e importante para o Brasil. Contudo, tem-se assistido uma exploração indiscriminada das matas naturais, sem ao menos existir a preocupação com formas alternativas para a conservação ou reposição dessas florestas (XAVIER e SANTOS, 2002).

A falta de técnicas na produção de mudas para espécies nativas e, em alguns casos, a falta de viabilidade de suas sementes, indicam a propagação vegetativa como alternativa na multiplicação dessas plantas, possibilitando a manutenção das boas características das plantas matrizes e a redução do período juvenil, o que leva à antecipação do mecanismo reprodutivo delas (RODRIGUES, 1990). Dentre as técnicas de propagação vegetativa, a estaquia revela-se como método economicamente viável para produção de novos indivíduos em curto período de tempo (PAIVA e GOMES, 1993).

No processo de enraizamento de estacas é comum a utilização de reguladores vegetais, dentre eles o ácido indolbutírico (AIB) que, além de estimular a iniciação radicial, promove o aumento da porcentagem de estacas enraizadas, acelera o tempo de formação das raízes e, conseqüentemente, diminui a permanência das estacas no leito de enraizamento (ALVARENGA e CARVALHO, 1983; HARTMANN et al., 2002).

Este trabalho buscou verificar a resposta do enraizamento de estacas caulinares semilenhosas de Tibouchina fothergillae, T. granulosa, T. pulchra e T. sellowiana, utilizando diferentes concentrações de ácido indolbutírico (AIB).

\section{MATERIAL E MÉTODOS}

A coleta do material vegetativo foi realizada na primavera de 2004, a partir de cinco plantas matrizes de T. fothergillae, T. granulosa, T. pulchra e T. sellowiana (figura 1) localizadas em um município de Curitiba (PR). Utilizaram-se estacas caulinares semilenhosas, com 10 $\mathrm{cm}$ de comprimento cortadas em bisel na base, além de duas folhas com sua área reduzida à metade, na porção distal.

Como tratamento fitossanitário, as estacas ficaram submersas em hipoclorito de sódio a $0,5 \%$ (P.A.) por 10 minutos, sendo posteriormente lavadas em água corrente. Em seguida, realizou-se a imersão das bases das estacas em soluções alcoólicas $(50 \%)$ com diferentes concentrações de ácido indolbutírico (AIB), por um período de 10 segundos. Os tratamentos foram os seguintes: $0 \mathrm{mgL}^{-1}, 1500 \mathrm{mgL}^{-1}$ e $3000 \mathrm{mgL}^{-1}$ AIB.

Após os tratamentos, acondicionaram-se as estacas em tubetes de polipropileno, de $53 \mathrm{~cm}^{3}$, com vermiculita de granulometria média como substrato e levados para casa de vegetação climatizada ( $25 \pm 2^{\circ} \mathrm{C}$ e $95 \%$ UR), localizada nas dependências do Setor de Ciências Biológicas da Universidade Federal do Paraná, em Curitiba (PR), e controlada por sensores de temperatura e umidade e sombreada por aluminet $50 \%$, por 30 dias para $T$. fothergillae, em virtude do rápido resultado do enraizamento já constatado em testes preliminares. As demais espécies foram mantidas na casa de vegetação por 70 dias, quando se verificou a porcentagem de enraizamento, número e comprimento das raízes formadas, porcentagem de estacas com calos (estacas vivas, sem raízes), sobrevivência (estacas vivas, sem calos ou raízes) e mortalidade destas.

Os dados foram analisados segundo um delineamento inteiramente casualizado com arranjo fatorial $3 \times 4$ (concentrações de AIB x espécies do gênero Tibouchina), com 4 repetições, 20 estacas por parcela. As variâncias dos tratamentos foram testadas quanto à homogeneidade pelo teste de Bartlett. Aquelas que se mostraram homogêneas foram submetidas à análise da variância e as que apresentaram diferenças significativas pelo teste de $\mathrm{F}$ tiveram suas médias comparadas pelo teste de Tukey ao nível de 5\%.

\section{RESULTADOS E DISCUSSÃO}

A análise da variância dos dados obtidos para o parâmetro porcentagem de enraizamento e de mortalidade revelou que a interação entre os fatores concentrações e espécies estudadas não foi estatisticamente significativa, indicando que esses fatores foram independentes. Assim, houve comparação das médias finais para a variável enraizamento e mortalidade (tabela 1).

A variável sobrevivência (estacas sem calos ou raízes) não foi analisada estatisticamente porque apenas a espécie T. sellowiana apresentou estacas vivas (11,67\%). Também não se constatou a presença de estacas com calos nas quatro espécies estudadas.

Como os resultados obtidos para a porcentagem de enraizamento e de mortalidade para as estacas de $T$. fothergillae foram $100 \%$ e $0 \%$, respectivamente, essas variáveis não foram incluídas na análise da variância apenas mencionadas na comparação de médias. 
Para as diferentes concentrações aplicadas de ácido indolbutírico (tabela 2), na porcentagem de enraizamento houve superioridade do tratamento com $3000 \mathrm{mgL}^{-1}$ AIB $(59,68 \%)$ sobre os demais, diferindo estatisticamente destes.

Espécies vegetais cujas estacas não enraízam bem em condições naturais, ao serem tratadas com AIA (ácido indol acético) ou seus análogos sintéticos como AIB emitem raízes com facilidade (ALVARENGA e CARVALHO, 1983).

Ao analisar o comportamento das diferentes espécies de Tibouchina ao enraizamento, torna-se evidente o sucesso das estacas de $T$. fothergillae, que enraizaram $100 \%$, seguidas das de $T$. sellowiana e $T$. pulchra, com $57,50 \%$ e $26,67 \%$, respectivamente, e da $T$. granulosa, com apenas $16,67 \%$ de enraizamento (tabela 2 ).

MAYER et al. (2003) tratando estacas semilenhosas de $T$. fothergillae com 0, 2000, 4000 e $8000 \mathrm{mgL}^{-1}$ AIB em solução também obtiveram $100 \%$ de enraizamento para todos os tratamentos, com exceção da aplicação de 8000 $\mathrm{mgL}^{-1}$ AIB (89,6\%). RIBEIRO et al. (2007), da mesma forma, registraram o sucesso do enraizamento de estacas testemunha de $T$. fothergillae, com $94 \%$ de enraizamento.

Já KNAPIK et al. (2003), em estudos que tinham por finalidade promover o enraizamento de estacas caulinares semilenhosas de $T$. pulchra, coletadas na primavera, obtiveram as maiores médias para porcentagem de enraizamento com a aplicação de $2000 \mathrm{mgL}^{-1} \mathrm{AIB}$ e $4000 \mathrm{mgL}^{-1} \mathrm{AIB}$, correspondendo a $28 \%$ de enraizamento em ambos os tratamentos.

LIMA et al. (2006) em pesquisa das diferentes espécies do gênero Calliandra registraram diferenças no enraizamento, obtendo apenas $5,83 \%$ de enraizamento para estacas de $C$. tweediei, enquanto estacas de $C$. sello $i$, com estames brancos, enraizaram $61,67 \%$ e a mesma espécie, com estames rosa, apresentou $54,17 \%$ de enraizamento. Diferenças na habilidade de enraizamento entre espécies do mesmo gênero foram assinaladas por DAWSON e KING (1994), DANTHU et al. (2002) e BONA et al. (2004).

Quanto à variável porcentagem de mortalidade, dentre as diferentes concentrações aplicadas de ácido indolbutírico (AIB), $3000 \mathrm{mgL}^{-1} \mathrm{AIB}$ foi a que apresentou a menor porcentagem $(38,06 \%)$, sobre os demais tratamentos, diferindo estatisticamente (tabela 2). BORTOLINI (2006), ao analisar o enraizamento de estacas de $T$. sellowiana, coletadas na primavera, obteve diminuição da mortalidade com o aumento de concentração de AIB, sendo $15 \%$ de mortalidade para estacas tratadas com $3000 \mathrm{mgL}^{-1}$ ou $\mathrm{mgKg}^{-1}$ de AIB, tratamentos estes que diferiram estatisticamente da testemunha $(35,63 \%)$.

Quando analisado o comportamento das diferentes espécies de Tibouchina, T. granulosa foi a que apresentou a maior porcentagem de mortalidade das estacas $(83,33 \%)$, seguida de $T$. pulchra $(73,33 \%)$ e $T$. sellowiana $(30,83 \%)$ (tabela 2). KNAPIK et al. (2003) obtiveram a média de $30 \%$ de mortalidade para estacas de $T$. pulchra colhidas na primavera.

T. granulosa, provavelmente, é a mais sensível das espécies estudadas quanto à desidratação da estaca durante o período de enraizamento, haja vista o alto índice de mortalidade. Uma das principais causas para a morte do caule é a dessecação, pois a falta de raízes impossibilita a absorção de água suficiente, e as folhas presentes, assim como as novas brotações, continuam perdendo água por transpiração (JANICK, 1966).

NACHTIGAL et al. (1994) atribuíram a alta mortalidade de estacas semilenhosas de araçazeiro ao pequeno grau de lignificação dos tecidos do material utilizado, proporcionando, assim, maior perda de água e, conseqüentemente, morte das estacas, embora estivessem em ambiente com nebulização intermitente. Esta seria outra possível causa para alta mortalidade das estacas de $T$. granulosa, visto que apresentava menor lignificação dentre as espécies estudadas.

Pela análise realizada, verifica-se efeito significativo das concentrações aplicadas, das espécies em estudo e da interação entre os fatores, para as variáveis número de raízes formadas por estacas e comprimento médio das três maiores raízes (tabela 1 ).

Estacas de $T$. fothergillae apresentaram o maior número de raízes formadas por estaca quando tratadas com $3000 \mathrm{~m} \mathrm{~g}^{-1} \mathrm{~A} \operatorname{IB}(39,57)$, estacas das demais espécies não diferiram estatisticamente entre os tratamentos (tabela 2). MAYER et al. (2003) obtiveram em estacas testemunhas de $T$. fothergillae a média de 12,65 raízes por estaca valor inferior ao resultado do tratamento sem o regulador vegetal $(22,41)$ do presente trabalho.

Em relação ao comprimento médio das três maiores raízes formadas, houve apenas diferença estatística significativa, dentre as concentrações utilizadas, para estacas de T. pulchra. O uso de $1500 \mathrm{mgL}^{-1} \mathrm{AIB}$ e 3000 $\mathrm{mgL}^{-1} \mathrm{AIB}$ proporcionou melhor resultado (12,91 e 12,53 $\mathrm{cm}$ ), diferindo da testemunha. As espécies que apresentaram as maiores raízes formadas foram $T$. granulosa e T. pulchra (tabela 2).

A formação de um número favorável de raízes e seu bom desenvolvimento podem demonstrar a qualidade do sistema radicial que se formou. Desse modo, as mudas terão maiores chances de sobrevivência e desenvolvimento mais vigoroso e rápido, proporcionando melhor fixação quando forem transplantadas para o campo (REIS et al., 2000).

A variação no comportamento de cada espécie no que se refere ao enraizamento, poderia ser causada pela presença de inibidores do enraizamento, freqüentes em plantas matrizes lenhosas e adultas (BAUER et al., 1999), ou por fatores anatômicos, característicos de cada espécie, que dificultariam a formação e/ou emergência das raízes. Para estacas de Griselinia lucida, o período de enraizamento foi mais lento e de menor êxito do que para estacas de $G$. littoralis que apresentaram menor número de fibras de esclerênquima (WHITE e LOVELL, 1984). BORTOLINI (2006), realizando o estudo anatômico da base das estacas de T. sellowiana, não registrou nenhuma barreira anatômica que pudesse prejudicar o enraizamento dessa espécie. Estudos anatômicos desse tipo poderiam, talvez, explicar o insucesso, registrado neste trabalho, do enraizamento das estacas de $T$. granulosa.

Além de inibidores químicos e barreiras anatômicas, outros fatores podem interferir no processo 
de enraizamento. Para espécies de difícil enraizamento da família Proteaceae, genótipo e estação de coleta influenciaram no desenvolvimento das raízes. Estacas de Banksia hookeriana e B. priomotes, coletadas de oito plantas de cada espécie, em intervalos de 2 meses durante um ano, apresentaram variação na habilidade individual da mesma espécie ao enraizamento (média de 0 a $80 \%$ ) (SEDGLEY et al., 1991 citado por BAUER et al., 1999).

O comportamento diferenciado para o enraizamento de estacas semilenhosas entre espécies do mesmo gênero ou até cultivares também pode ser atribuído à constituição genética e às condições físiológicas de cada uma (SHARMA e AIER, 1989), podendo ainda diferir quanto à concentração de AIB aplicada e à época de coleta (KERSTEN et al., 1994).

\section{CONCLUSÕES}

O uso do ácido indolbutírico (AIB) mostrou-se efetivo sobre a indução radicial nas estacas caulinares das espécies estudas, com exceção de $T$. fothergillae, que mesmo sem a aplicação do regulador vegetal respondeu com sucesso ao enraizamento.

Recomenda-se a aplicação de $3000 \mathrm{mgL}^{-1} \mathrm{AIB}$ em estacas caulinares de T. sellowiana, T. pulchra e $T$. granulosa para maior indução do sistema radicial.

T. fothergillae foi a espécie que apresentou o maior enraizamento, seguida de T. sellowiana, T. pulchra e $T$. granulosa.

\section{REFERÊNCIAS}

ALVARENGA, L.R.; CARVALHO, V.D. Uso de substâncias promotoras de enraizamento de estacas frutíferas. Informe Agropecuário, Belo Horizonte, v.9, n.101, p.47-55, 1983.

BARROSO, G.M. Sistemática de Angiospermas do Brasil. Viçosa, UFV: Imprensa Universitária. v.2, 1991. $377 \mathrm{p}$.

BAUER, L.M.; JOHNSTON, M.E.; WILLIAMS, R.R. Plant genotype, juvenility and mechanisms of inhibition of rooting Persoonia virgata $\mathrm{R}$. Br. Cuttings. Australian Journal of Experimental Agriculture, Melbourne, v.39, p.1029-1034, 1999.

BONA, C.M.; BIASI, L.A.; ZANETTE, F.; NAKASHIMA, T. Propagação de três espécies de carqueja com estacas de diferentes tamanhos. Semina Ciências Agrárias, Londrina, v.25, n.3, p.179-184, 2004.

BORTOLINI, M.F. Uso de ácido indol butírico na estaquia de Tibouchina sellowiana (Cham.) Cogn. Curitiba, UFPR, 2006. 85p. Dissertação (Mestrado em Agronomia)

DANTHU, P.; SOLOVIV, P.; GAYE, A.; SARR, A.; SECK, M.; THOMAS, I. Vegetative propagation of some West African Ficus species by cuttings. Agroforestry Systems, Netherllands, v.55, p.57-63, 2002.
DAWSON, I.A.; KING, R.W. Propagation of some woody Australian plants from cuttings. Australian Journal of Experimental Agriculture, Collingwood, v.34, p.12251231, 1994.

HARTMANN, H.T.; KESTER, D.E.; DAVIS JÚNIOR, F.T; GENEVE, R.L. Plant Propagation: Principles and Practices. 7.ed. New York: Englewood Clipps. 2002. 880p.

JANICK, J. A ciência da horticultura. Rio de Janeiro: F. Bastos. 1966. 485p.

KERSTEN, E.; TAVARES, S.W.; NACHTIGAL, J.C.; Influência do ácido indolbutírico no enraizamento de estacas de ameixeira (Prunus salicina, Lindl.). Revista Brasileira de Fruticultura, Cruz das Almas, v.16, n.1, p.215-222, 1994.

KNAPIK，J.G.; ZUFFELLATO-RIBAS， K.C.; CARPANEZZI, A.A.; TAVARES, F.R.; KOEHLER, H.S. Influência da época de coleta e da aplicação de ácido indol butírico na propagação por estaquia da Tibouchina pulchra (Cham.) Cogn. (quaresmeira). Iheringia, Série Botânica, Porto Alegre, v.58, n.2, p.171-179, 2003.

LIMA D.M. de.; ALCANTARA, G.B. de.; BORTOLINI, M.F.; FANTI, F.P.; BIASI, L.A.; QUOIRIN, M.; KOEHLER, H.S.; ZUFFELLATO-RIBAS, K.C. Substratos e concentrações de ácido naftaleno acético no enraizamento de estacas semilenhosas de Calliandra sello $i$ e Calliandra tweendiei. Scientia Agraria, Curitiba, v.7, n.1-2, p.105-111, 2006.

LIMA, J.A.S. de; MENEGUELLI, N.A. do; FILHO, A.B.G.; PÉREZ, D.V. Agrupamento de espécies arbóreas de uma floresta tropical por características de solo. Pesquisa Agropecuária Brasileira, Brasília, v.38, n.1, 2003.

MAYER, J.L.; ZUFFELLATO-RIBAS, K.C.; BONA, C.; RIBAS, L.L.F.; CARPANEZZI, A.A.; TAVARES, F.R. Enraizamento e anatomia de estacas de Tibouchina fothergillae (DC.) Cogn. (Melastomataceae). In: IX CONGRESSO BRASILEIRO DE FISIOLOGIA VEGETAL, Atibaia, 2003. Caderno de resumos. Atibaia: Brasilian journal of Plant Physiology, 2003. 148p.

MORAES, R.M. de; DELITTI, W.B.C.; MORAES, J.A.P.V. de. Respostas de indivíduos jovens de Tibouchina pulchra Cogn. à poluição aérea de Cubatão, SP: fotossíntese líquida, crescimento e quim ica forrar. Revista Brasileira de Botânica, São Paulo, v.23, n.4, p.444-449, 2000.

NACHTIGAL, J.C.; HOGGMANN, A.; KLUGE, R.A.; FACHINELLO, J.C.; MAZZINI, A.R.A. de. Enraizamento de estacas semilenhosas de araçazeiro (Psidium cattleyanum Sabine) com o uso do ácido indolbutírico. Revista Brasileira de Fruticultura, Cruz das Almas, v.16, n.1, p.229-235, 1994.

PAIVA, H.N. de.; GOMES, J.M. Propagação Vegetativa 
de espécies florestais. Minas Gerais: Imprensa Universitária. 1993. 40p.

PIO CORRÊIA. Dicionário de Plantas úteis do Brasil. Rio de Janeiro: Ministério da Agricultura. v.3, 1974. 646p.

REIS, J.M.R.; CHALFUN, N.N.J.; LIMA,L. C.O.; LIMA, L.C. Efeito do estiolamento e do ácido indolbutírico no enraizamento de estacas do porta-enxerto Pyrus calleryana Dcne. Ciência Agrotécnica, Lavras, v.24, n.4, p.931-938, 2000.

RIBEIRO, M.N. de. O.; PAIVA, P.D.O. de., SILVA, J. da. C.B.; PAIVA, R. Efeito de ácido indolbutírico sobre estacas apicais e medianas de quaresmeira (Tibouchina fothergillae Cogn.). Revista Brasileira de Horticultura Ornamental, Campinas, v.13, n.1, p.73-78, 2007.

RODRIGUES, V.A. Propagação vegetativa de Aroeira Schinus terebinthifolius Raddi Canela Sassafrás Ocotea pretiosa Benth \& Hook e Cedro Cedrela fissilis Vellozo através de estacas radiciais e caulinares. UFPR : Curitiba, 1990, 90p. Dissertação (Mestrado em Engenharia Florestal).
SHARMA, S.D.; AIER, N.B. Seasonal rooting behaviour of cuttings of Plum cultivars as influenced by IBA trea tm en ts. Scientia Horticulturae, Amsterdan, v.40, p.297-303, 1989.

SOUZA, M.L.D.R. Estudo taxonômico do Gênero Tibouchina Aubl. (Melastomatacea) no Rio Grande do Sul, Brasil. Ínsula Boletim do Horto Botânico, Florianópolis, n. 16, 1986. 112p.

TABARELLI, M.; MANTOVANI, W. A riqueza de espécies arbóreas na floresta atlântica de encosta de São Paulo (Brasil). Revista Brasileira de Botânica, São Paulo, v.22, p.217-223, 1999.

WHITE, J.; LOVELL, P.H. The anatomy of root initiation in cuttings of Griselinia littoralis and Griselinia lúcida. Annals of Botany, London, v.54, p.7-20, 1984.

XAVIER, A. SANTOS, G. A. dos. Clonagem em espécies florestais nativas. IN: ROCHA, M.G.B. Melhoramento de espécies arbóreas nativas, Belo Horizonte: Instituto de desenvolvimento Florestal Sustentável - IEF. 2002. 173p.

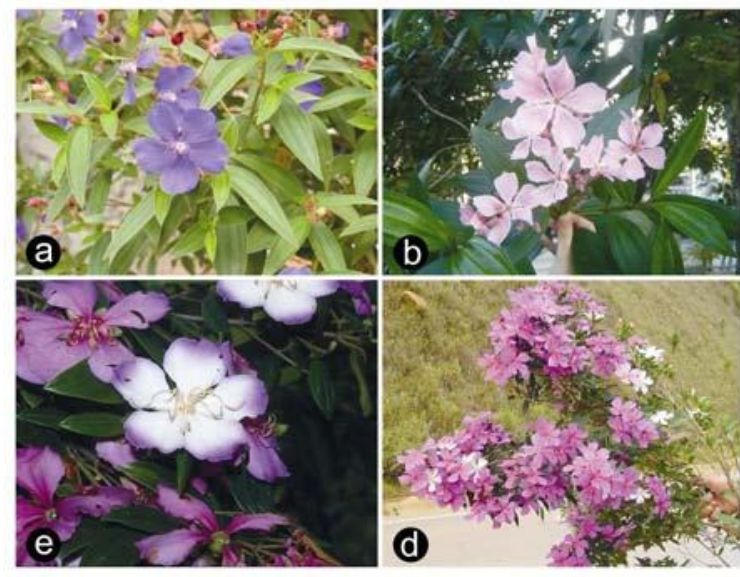

Figura 1. Tibouchina estudadas. A. T. fotergillae, B. T. granulosa, C. T. pulchra, D. T. sellowiana. Figure 1. Studied Tibouchina. A. T. fotergillae, B. T. granulosa, C. T. pulchra, D. T. sellowiana.

Tabela 1. Análise da variância (teste F), dos resultados obtidos para as quatro espécies de Tibouchina para a porcentagem de estacas enraizadas e mortas, número de raízes formadas e comprimento médio das três maiores raízes $(\mathrm{cm})$

Table 1. Analysis of variance (test F), the results gotten for the four species of Tibouchina, for rooting and mortality cuttings, number of root and medium length of three larger roots (cm)

\begin{tabular}{|c|c|c|c|c|c|c|}
\hline \multirow[t]{2}{*}{ Causa da variação } & \multirow[t]{2}{*}{ G.L } & \multicolumn{2}{|c|}{$\mathrm{F}$} & \multicolumn{3}{|c|}{$\mathrm{F}$} \\
\hline & & Enraizadas & Mortas & GL & $\begin{array}{l}\text { Número } \\
\text { de raízes }\end{array}$ & $\begin{array}{c}\text { Comprimento } \\
\text { médio }\end{array}$ \\
\hline Concentração (C) & & $12, \unrhd 3^{*}$ & $13,16^{*}$ & 2 & $39,09^{*}$ & $7,69^{*}$ \\
\hline Espécie (E) & 2 & $41,20^{*}$ & $100,20^{*}$ & 3 & $811,80^{*}$ & $78,54^{*}$ \\
\hline Interação C x E & 4 & $2,31^{\mathrm{ns}}$ & $0,43^{\mathrm{ns}}$ & 6 & $25,86^{*}$ & $5,06^{*}$ \\
\hline Erro & 27 & & & 36 & & \\
\hline Total & 35 & & & 47 & & \\
\hline Coeficiente de variação (\%) & & 34,18 & 15,43 & & 13,96 & 11,26 \\
\hline
\end{tabular}


Tabela 2. Comparação de médias para as variáveis analisadas entre as diferentes concentrações de ácido indolbutírico (AIB) e as quatro espécies de Tibouchina estudadas

Table 2. Comparison of averages for the variable analyzed between the different concentrations of indolebutyric acid(IBA) and the four species of studied Tibouchina

\begin{tabular}{|c|c|c|c|c|}
\hline \multirow{2}{*}{ Espécie } & \multicolumn{3}{|c|}{ Concentrações de ácido indolbutírico (AIB) } & \multirow{2}{*}{ Médias } \\
\hline & $0 \mathrm{mgL}^{-1}$ & $1500 \mathrm{mgL}^{-1}$ & $3000 \mathrm{mgL}^{-1}$ & \\
\hline \multicolumn{5}{|c|}{ Porcentagem de enraizamento } \\
\hline T. fothergillae & 100,00 & 100,00 & 100,00 & 100,00 \\
\hline T. granulosa & 13,75 & 11,25 & 25,00 & $16,67 \mathrm{~B}$ \\
\hline T. pulchra & 21,25 & 20,00 & 38,75 & $26,67 \mathrm{~A}$ \\
\hline T. sellowiana & 36,25 & 61,25 & 75,00 & $57,50 \mathrm{~A}$ \\
\hline Médias & $42,81 \mathrm{~b}$ & $48,12 \mathrm{~b}$ & $59,68 \mathrm{a}$ & \\
\hline \multicolumn{5}{|c|}{ Porcentagem de mortalidade } \\
\hline T. fothergillae & 0,00 & 0,00 & 0,00 & 0,00 \\
\hline T. granulosa & 86,25 & 88,75 & 75,00 & $83,33 \mathrm{~A}$ \\
\hline T. pulchra & 78,75 & 80,00 & 61,25 & $73,33 \mathrm{~B}$ \\
\hline T. sellowiana & 40,00 & 36,25 & 16,25 & $30,83 \mathrm{C}$ \\
\hline Médias & $51,18 \mathrm{a}$ & $51,25 \mathrm{a}$ & $38,06 \mathrm{~b}$ & \\
\hline \multicolumn{5}{|c|}{ Número de raízes } \\
\hline $\begin{array}{l}\text { T. fothergillae } \\
\text { T. granulosa } \\
\text { T. pulchra } \\
\text { T. Sellowiana }\end{array}$ & $\begin{array}{c}22,41 \mathrm{Ac} \\
5,12 \mathrm{BCa} \\
2,67 \mathrm{Ca} \\
6,41 \mathrm{Ba}\end{array}$ & $\begin{array}{c}34,21 \mathrm{Ab} \\
4,00 \mathrm{Ba} \\
3,67 \mathrm{Ba} \\
6,20 \mathrm{Ba}\end{array}$ & $\begin{array}{l}39,57 \mathrm{Aa} \\
5,74 \mathrm{BCa} \\
3,63 \mathrm{Ca} \\
8,26 \mathrm{Ba}\end{array}$ & $\begin{array}{c}32,10 \\
4,96 \\
3,32 \\
6,95\end{array}$ \\
\hline Médias & 9,15 & 12,10 & 14,30 & \\
\hline \multicolumn{5}{|c|}{ Comprimento médio $(\mathrm{cm})$} \\
\hline $\begin{array}{l}\text { T. fothergillae } \\
\text { T. granulosa } \\
\text { T. pulchra } \\
\text { T. sellowiana }\end{array}$ & $\begin{array}{r}5,37 \mathrm{Ca} \\
13,14 \mathrm{Aa} \\
8,68 \mathrm{Bb} \\
8,38 \mathrm{Ba}\end{array}$ & $\begin{array}{r}6,71 \mathrm{Ca} \\
11,62 \mathrm{Aa} \\
12,91 \mathrm{Aa} \\
9,04 \mathrm{Ba}\end{array}$ & $\begin{array}{r}6,61 \mathrm{Ca} \\
12,94 \mathrm{Aa} \\
12,53 \mathrm{Aa} \\
9,18 \mathrm{Ba}\end{array}$ & $\begin{array}{c}6,23 \\
12,57 \\
11,37 \\
8,87\end{array}$ \\
\hline Médias & 8,90 & 10,07 & 10,32 & \\
\hline
\end{tabular}

